\title{
AVALIAÇÃO \\ ORGANIZACIONAL DE PLANOS MUNICIPAIS DE EDUCAÇÃO RELATIVOS AO PNE 2014-2024
}

DONALDO BELLO DE SOUZA

\section{RESUMO}

O presente artigo se propõe a avaliar a organização interna dos Planos Municipais de Educação (PMEs) da Região Metropolitana do Rio de Janeiro, de modo a verificar sua consonância em relação ao Plano Nacional de Educação (PNE) 2014-2024. Elege como dimensões de análise a normatização jurídica, o diagnóstico da situação educacional e a definição das metas e estratégias. Constata que dos 19 PMEs analisados, apenas nove não expõem maiores problemas em relação à sua estrutura e organização, enquanto que os outros dez apresentam adversidades significativas concernentes a uma ou mais dimensões examinadas, sendo que, desses, três exibem importantes desalinhamentos em relação a esse novo PNE. Em contrapartida, destaca os avanços expostos por esses planos, também salientando a pertinência da continuidade e aprofundamento de suas avaliações, indicando outras dimensões analíticas possíveis de serem contempladas.

PALAVRAS-CHAVE PLANO MUNICIPAL dE EDUCAÇÃO - PLANO NACIONAL DE EDUCAÇÃO • REGIÃO METROPOLITANA • ESTADO DO RIO DE JANEIRO. 


\section{EVALUACIÓN DE LA ORGANIZACIÓN DE LOS PLANES MUNICIPALES DE EDUCACIÓN RELACIONADOS A EL PNE 2014-2024}

RESUMEN

El presente artículo tiene el objetivo de evaluar la organización interna de los Planes Municipales de Educación (PMEs) de la región metropolitana de Río de Janeiro, a fin de comprobar si están conformes con el Plan Nacional de Educación (PNE) 2014-2024. Elige como dimensiones de análisis la regulación jurídica, el diagnóstico de la situación educativa y la definición de las metas y estrategias. Constata que de los 19 PMEs analizados, solamente nueve no exponen problemas importantes en lo que concierne a su estructura y organización, mientras que los otros diez presentan adversidades significativas relativas a una o más dimensiones examinadas, $y$, de éstos, tres exponen importantes desajustes en relación al nuevo PNE. En contrapartida, destaca los avances expuestos por estos planes, enfatizando también la importancia de la continuidad y la profundización de sus evaluaciones, indicando otras dimensiones analíticas a considerar.

PALABRAS CLAVE PLAN MUNICIPAL DE EDUCACIÓN - PLAN NACIONAL DE EDUCACIÓN・REGIÓN METROPOLITANA・ESTADO DE RIO DE JANEIRO.

\section{EVALUATION OF THE ORGANIZATION OF MUNICIPAL EDUCATION PLANS RELATED TO THE PNE 2014-2024}

ABSTRACT

The present article aims to evaluate the internal organization of Municipal Education Plans (PMEs) of the Metropolitan Region of Rio de Janeiro, in order to check its alignment with the National Education Plan (PNE) 2014-2024. The legal norms as well as the diagnosis of the education situation and the definition of the goals and strategies are used as instruments of analysis. It was observed that, of the 19 PMEs analyzed, only nine do not present major problems in relation to their structure and organization, while the other ten have significant problems related to one or more dimensions examined and, of these, three present important misalignments relative to this new PNE. On the other hand, the advances made by these plans are emphasized, also stressing the importance of continuity and deepening of their evaluations, indicating other analytical dimensions to be considered.

KEYWORDS MUNICIPAL EDUCATION PLAN • NATIONAL EDUCATION PLAN • METROPOLITAN REGION • STATE OF RIO DE JANEIRO. 
1 Segundo dados constantes da página do Ministério da Educação (MEC), denominada PNE em Movimento - Situação dos Planos de Educação, dos 26 estados da federação, até fins de julho de 2016 apenas Rio de Janeiro e Minas Gerais não tinham PEE transformados em norma jurídica: o primeiro estado tendo unicamente o documento-base do plano elaborado, enquanto que o segundo aguardando o trâmite na Assembleia Legislativa. Disponíve em: <pne.mec.gov.br/planos-deeducacao/situacao-dos-planos-deeducacao>. Acesso em: 29 jul. 2016.

2 Ver: <http://pne.mec.gov.br/planosde-educacao/situacao-dos-planos-deeducacao>. Acesso em: 29 jul. 2016

3 Será nos idos de 1970 que a expansão urbana no Brasil ocorrerá em meio à formação das grandes regiões metropolitanas (RMs) (BRITO, 2006), embora algumas experiências isoladas de administração metropolitana se fizessem notar desde a década de 1960, por iniciativa de alguns governos estaduais que criaram áreas metropolitanas nas capitais: São Paulo Porto Alegre, Belém, Salvador e Belo Horizonte (ROLNIK; SOMEKH, 2000)

\section{INTRODUÇÃO}

Em que pese o fato de o Rio de Janeiro, até fins julho de 2016, ainda não dispor do seu Plano Estadual de Educação (PEE) consoante ao Plano Nacional de Educação (PNE) 2014-2024 - Lei n. 13.005, de 25 de junho de 2014 (BRASIL, 2014a) ${ }^{1}$-, constata-se que, até aquela data, 89 (97\%) das 92 localidades fluminenses já haviam procedido à transformação dos seus novos Planos Municipais de Educação (PMEs) em norma jurídica. Nesse sentido, essas cidades, à exceção da capital (Rio de Janeiro) e Niterói - cujos PMEs ainda tramitavam nas respectivas câmaras municipais $-^{2}$, já se encontravam com seus planos aprovados pelo Legislativo, sancionados pelo Executivo e, ainda, publicados em órgão oficial. Em escala regional, observa-se, também, que, das 21 localidades que presentemente compõem a Região Metropolitana do Rio de Janeiro (RMRJ), 19 (90\%) já dispunham dos seus planos assim regulamentados.

A RMRJ, também denominada Grande Rio, veio a ser estabelecida por meio da Lei Complementar (LC) n. 20, de 1 de julho de 1974 (BRASIL, 1974), ${ }^{3}$ que, no Capítulo II, determinou a fusão dos estados do Rio de Janeiro e da Guanabara, 
o que também significou união entre as regiões metropolitanas (RMs) do Grande Rio Fluminense e da Grande Niterói. Inicialmente delimitada a 14 municípios, ${ }^{4}$ a RMRJ veio, ao longo dos anos, sendo modificada pela exclusão e inclusão de localidades, integrando, em 2010, 19 municípios. ${ }^{5}$ Mais recentemente, em função da LC n. 158, de 26 de dezembro de 2013 (RIO DE JANEIRO, 2013), mais duas cidades passaram a integrá-la, ${ }^{6}$ totalizando 21 municípios.

Inicialmente, cabe destacar que aquela elevada taxa (97\%) de elaboração dos PMEs do estado do Rio de Janeiro alinhados ao PNE 2014-2024 representa um grande avanço em termos do esforço, em tese, de tornar o planejamento local da educação menos experimental, intuitivo e fragmentado, e, por conseguinte, mais projetivo, racional e sistematizado, aspectos que, entre outros, servem à caracterização desses planos decenais (BORDIGNON, 2014; DIDONET, 2000, 2001; MARTINS, 2012; MENDONÇA, 2002; VIEIRA, 2014). Em razão de se constituírem em políticas de Estado, esses planos passam também a apresentar menor vulnerabilidade às sazonalidades das políticas de governo para a área da educação. ${ }^{7}$ Assim, afirmam-se com maior perenidade na medida em que, por um lado, têm duração de dez anos, e não vulnerável aos quatro anos dos mandatos governamentais, e, de outro, para serem alterados ou revogados, impõem, no mínimo, debate no interior dos órgãos públicos responsáveis por sua normatização jurídica, especialmente por parte das casas legislativas, podendo (e devendo), em função do grau de democratização do município, envolver a comunidade local (BORDIGNON, 2014).

Especificamente em relação aos PMEs da RMRJ alinhados ao extinto PNE 2001-2010 (BRASIL, 2001), nota-se que o número de novos planos, consoantes ao PNE 2014-2024 (BRASIL, 2014a), praticamente dobrou (de dez para 19). Segundo Souza e Alcântara (2015, 2016), entre 2001 e 2012, de um universo de 19 municípios que, à época, definiam essa RM, apenas dez (53\%) tinham PMEs aprovados. Os autores observam, ainda, que, à exceção da cidade de Nilópolis, que regulamentou o plano em dezembro de 2001, todas as demais localidades vieram a ter seus planos transformados em
4 Duque de Caxias, Itaboraí, Itaguaí, Magé, Mangaratiba, Maricá, Nilópolis, Niterói, Nova Iguaçu, Paracambi, Petrópolis, Rio de Janeiro, São Gonçalo e São João do Meriti (BRASIL, 1974).

5 Belford Roxo, Duque de Caxias, Guapimirim, Itaboraí, Itaguaí, Japeri, Magé, Maricá, Mesquita, Nilópolis, Niterói, Nova Iguaçu, Paracambi, Queimados, Rio de Janeiro, São Gonçalo, São João de Meriti, Seropédica e Tanguá (RIO DE JANEIRO, 2010)

6 Rio Bonito e Cachoeiras de Macacu (RIO DE JANEIRO, 2013).

7 "Considera-se que políticas de governo são aquelas que o Executivo decide num processo elementar de formulação e implementação de determinadas medidas e programas, visando responder às demandas da agenda política interna, ainda que envolvam escolhas complexas. Já as políticas de Estado são aquelas que envolvem mais de uma agência do Estado, passando em geral pelo Parlamento ou por instâncias diversas de discussão, resultando em mudanças de outras normas ou disposições preexistentes, com incidência em setores mais amplos da sociedade" (OLIVEIRA, 2011, p. 329). 
8 Registram-se os agradecimentos às colegas Profa. Dra. Janaína Specht da Silva Menezes, da Faculdade de Educação da Universidade Federal do Estado do Rio de Janeiro (UNIRIO), e à Profa. Dra. Alzira Batalha Alcântara, da Faculdade de Educação da Baixada Fluminense/Universidade do Estado do Rio de Janeiro (FEBEF/UERJ), pelas importantes contribuições que implicaram aperfeiçoamento do presente estudo norma jurídica somente a partir do sexto ano de vigência daquele PNE, processo que se estendeu de 2006 a 2012, expondo elevada dissintonia em relação às metas definidas em escala nacional.

Contudo, é importante considerar que, em larga medida, o aumento da adesão dos municípios da RMRJ a esse tipo de planejamento, assim como o ocorrido em relação às demais localidades do país, decorre da precisão, até mesmo temporal, com que o PNE 2014-2024 determina aos entes federados (estados, Distrito Federal e municípios) a elaboração dos planos de educação correspondentes ou a adequação dos planos já aprovados em lei, "em consonância com as diretrizes, metas e estratégias previstas nesse PNE, no prazo de 1 (um) ano contado da publicação desta Lei” (BRASIL, 2014a, art. $8^{\circ}$ ). Importante observar que, no caso do PNE 2001-2010, a lei que o regulamentou - Lei n. 10.172, de 9 de janeiro de 2001 - apenas dispunha que esses entes federados deveriam "com base no Plano Nacional de Educação, elaborar planos decenais correspondentes" (BRASIL, 2001, art. $2^{\circ}$ ).

Não obstante o reconhecimento do valor desses avanços para a profissionalização da gestão local da educação e em continuidade aos estudos de Souza e Alcântara $(2015,2016)$, o presente artigo se propõe a avaliar a organização interna dos PMEs da RMRJ, de modo a aferir sua consonância em relação ao PNE 2014-2024. Elege, como dimensões de análise, a normatização jurídica, o diagnóstico da situação educacional e a definição das metas e estratégias, abordando-os de forma exploratória (KETELE; ROEGIERS, 1993) e por meio de incursões comparativas (YANG, 2015) relativas não apenas ao PNE, mas entre os próprios PMEs, isso com foco nos documentos legislativos correspondentes - leis de criação e seus anexos (planos propriamente ditos) - e tomando por referência os marcos jurídicos e a literatura acadêmica correlata. Cada uma dessas dimensões é, portanto, respectivamente examinada nas três seções que se seguem a esta introdução, quando, após, são estabelecidas as conclusões do estudo, com vistas à formulação final da avaliação em causa. ${ }^{8}$ 


\section{NORMATIZAÇÃO JURÍDICA DOS PMES}

Com base no Quadro 1, observa-se que, transcorridos 12 meses da aprovação do PNE 2014-2024, apenas dez (47\%) dos 21 municípios da RMRJ tinham PMEs transformados em norma jurídica, o que significa que vieram a ter seus planos efetivamente aprovados no prazo estabelecido na Lei n. 13.005/2014, qual seja, "de 1 (um) ano contado da publicação desta Lei” (BRASIL, 2014a, art. $8^{\circ}$ ), a saber, Belford Roxo, Cachoeiras de Macacu, Guapimirim, Itaboraí, Japeri, Nova Iguaçu, Paracambi, Rio Bonito, São João de Meriti e Tanguá.

Daquele total de 21 localidades, constata-se que outros nove (43\%) municípios vieram a ter os seus PMEs aprovados e publicados após essa data: Duque de Caxias, Itaguaí, Magé, Mesquita, Queimados e Seropédica, com menos de um mês de atraso; Maricá e Nilópolis, com cerca de três meses; e São Gonçalo, com retardo de quase seis meses. Todavia, tais defasagens temporais em relação à consecução do PNE são passíveis de serem consideradas de baixo impacto para o planejamento decenal nacional, na medida em que não sugerem implicar reduções significativas nos tempos máximos definidos para alcance das metas nacionalmente fixadas.

De fato, os casos mais graves consistem nos PMEs de Niterói e Rio de Janeiro que, pelo menos até o final do mês de julho de 2016, ou seja, dois anos após a sanção do PNE 2014-2024 e um ano seguinte ao término do prazo fixado na sua lei, ainda não tinham PMEs transformados em norma jurídica, encontrando-se em trânsito nas respectivas câmaras municipais. ${ }^{9}$
9 Disponível em: <http://pne.mec.gov. $\mathrm{br} /$ planos-de-educacao/situacao-dosplanos-de-educacao >. Acesso em: 29 jul. 2016. 
QUADRO 1 - Enquadramento jurídico dos PMEs da RMRJ articulados ao PNE 2014-2024

\begin{tabular}{|c|c|c|c|}
\hline REFERÊNCIA PME & LEI № & $\begin{array}{c}\text { DATA DE } \\
\text { APROVAÇÃO }\end{array}$ & $\begin{array}{l}\text { PERÍODO DE } \\
\text { VIGÊNCIA }\end{array}$ \\
\hline Belford Roxo & 1.529 & 24 de junho de 2015 & $2015-2025$ \\
\hline Cachoeiras de Macacu & 2.056 & 24 de junho de 2015 & $2015-2025^{(*)}$ \\
\hline Duque de Caxias & 2.713 & 30 de junho de 2015 & $2015-2025$ \\
\hline Guapimirim & 859 & 24 de junho de 2015 & 2015-2025 \\
\hline Itaboraí & 2.556 & 22 de junho de 2015 & $2015-2025$ \\
\hline Itaguaí & 3.324 & 30 de junho de 2015 & 2015-2025 \\
\hline Japeri & 1.301 & 23 de junho de 2015 & $2015-2025$ \\
\hline Magé & 2.267 & O1 de julho de 2015 & $2015-2025^{(*)}$ \\
\hline Maricá & 2.613 & 17 de setembro de 2015 & 2015-2025 \\
\hline Mesquita & 908 & 29 de junho de 2015 & $2015-2025^{(*)}$ \\
\hline Nilópolis & 6.490 & O3 de setembro de 2015 & 2015-2024 \\
\hline Niterói & - & - & - \\
\hline Nova Iguaçu & 4.504 & 23 de junho de 2015 & $2015-2025$ \\
\hline Paracambi & 1.169 & 18 de junho de 2015 & $2015-2025$ \\
\hline Queimados & 1.251 & 15 de julho de 2015 & $2015-2025^{(*)}$ \\
\hline Rio Bonito & 2.070 & 23 de junho de 2015 & $2015-2025$ \\
\hline Rio de Janeiro & - & - & - \\
\hline São Gonçalo & 658 & O7 de dezembro de 2015 & $2015-2024$ \\
\hline São João de Meriti & 2.004 & 17 de junho de 2015 & 2014-2024 \\
\hline Seropédica & 566 & 1 de julho de 2015 & $2015-2025$ \\
\hline Tanguá & 971 & 24 de junho de 2015 & $2015-2025$ \\
\hline
\end{tabular}

Fonte: Dados da pesquisa (elaborado pelo autor em julho de 2016).

'Período não explicitado na lei nem no documento do PME correspondente, deduzido a partir da data de publicação do plano e da indicação do seu prazo de vigência (para todos os casos, decenal).

O Quadro 1 permite, ainda, depreender que grande parte desses 19 PMEs - 15 (79\%) - explicita, em seus documentos (no corpo da lei ou do plano propriamente dito), o intervalo de tempo de sua duração, enquanto que apenas quatro (21\%) unicamente assinalam que o plano entra em vigor a partir da data de sua publicação, como de praxe nos textos legislativos. Nesses casos, procedeu-se à dedução do período em questão, considerando-se a data de publicação do PME no órgão oficial e a indicação do tempo total de vigência explicitado (dez anos), como o ocorrido com os planos de Cachoeiras de Macacu, Magé, Mesquita e Queimados.

Assim, no seu conjunto, esses planos têm vigência decenal, correspondentemente ao período 2015-2025, à exceção de Nilópolis e São Gonçalo, que assinalam o período 2015-2024, sugerindo tratar-se de planos pautados no esquema de datação adotado pelo antigo PNE 2001-2010 (BRASIL, 2001), 
que considerava o ano de aprovação o primeiro ano de vigência decenal do plano propriamente dito. Já o PME de São João de Meriti, embora tenha sido aprovado em 17 de junho de 2015, indica o decênio 2014-2024 como aquele concernente à duração do plano, apresentando inconsistência em relação à data de início de sua vigência, que corresponde ao da sua publicação em órgão oficial.

De acordo com levantamento documental efetuado em torno desses 19 PMEs, ${ }^{10}$ cumpre também destacar que se logrou obter a publicação do plano e da lei correlata em órgão oficial referente a apenas nove (47\%) municípios - Cachoeiras de Macacu (2015), Guapimirim (2015), Maricá (2015), Mesquita (2015a, b), Nilópolis (2015), Nova Iguaçu (2015), Queimados (2015), São Gonçalo (2015a, 2015b) e São João de Meriti (2015). Em relação aos outros quatro (21\%) planos, conseguiu-se localizar apenas a publicação da lei em órgão oficial, mas excluída do texto do plano propriamente dito, conforme ocorrido com Belford Roxo (2015a), Duque de Caxias (2015a), Rio Bonito (2015a) e Seropédica (2015a). No que remete aos demais seis (32\%) planos - Itaboraí (2015), Itaguaí (2015a, b), Japeri (2015a, b), Magé (2015), Paracambi (2015) e Tanguá (2015) -, em que pese a identificação do texto da lei e do PME digitados ou digitalizados, não se conseguiu detectar as versões, de fato, publicadas em órgão oficial. ${ }^{11}$

Sobre as questões relacionadas à publicação da lei e/ou dos PMEs em órgão oficial, ${ }^{12}$ cumpre esclarecer que, conforme o determinado no art. $1^{\circ}$ da Lei de Introdução ao Código Civil Brasileiro - Decreto-Lei n. 4.657, de 4 de setembro de 1942 (BRASIL, 1942), cuja ementa veio a ser alterada pela Lei n. 12.376, de 30 de dezembro de 2010 para "Lei de Introdução às Normas do Direito Brasileiro" (BRASIL, 2010) -, "Salvo disposição contrária, a lei começa a vigorar em todo o país quarenta e cinco dias depois de oficialmente publicada" (BRASIL, 1942, art. $1^{\circ}$ ). Além disso, a própria Constituição Federal (CF) de 1988 (BRASIL, 1988, art. 84, IV) consagra o princípio da publicidade relativamente a tais atos normativos, na medida em que determina ao chefe do Poder Executivo que publique as leis aprovadas, princípio também enunciado no seu art. 37.
10 Em um primeiro momento o levantamento se pautou na identificação das leis e dos PMEs correlatos aos 19 municípios da RMRJ a partir da página da internet relativa ao MEC, intitulada PNE em Movimento: Situação dos Planos de Educação disponível em: <http://pne.mec.gov br/planos-de-educacao/situacaodos-planos-de-educacao> -, e ao Ministério Público do Estado do Rio de Janeiro (MPRJ) - disponível em: <http://www.mprj.mp.br/areas-deatuacao/educacao/controle-social-naeducacao/planos-de-educacao-dosmunicipios-do-rio-de-janeiro>. Em seguida, de modo a distinguir outras versões desses planos, procedeu-se à ampliação dos canais de busca, agora considerando, quando existentes, as bases pertencentes às câmaras municipais e aos diários oficiais (DOs) desses municípios, além da consulta às páginas das secretarias municipais de educação (SMEs) dos sistemas de ensino em questão.

11 Em complemento ao procedimento de busca descrito na nota acima, em 31 de maio de 2016 enviou-se mensagem por e-mail para a SME relativa ao conjunto desses dez municípios cujos planos apresentaram dificuldades de localização de publicação em órgão oficial - Belford Roxo, Duque de Caxias, Itaboraí, Itaguaí, Japeri, Magé, Paracambi, Rio Bonito, Seropédica e Tanguá -, sendo obtidas respostas apenas dos municípios de Duque de Caxias e Mesquita, embora não suficientemente esclarecedoras.

12 De acordo com Soares (2008, grifos do autor), é de competência do ente federado a definição da forma de publicidade dos atos editados, "Mas, conforme reconhecido pelo próprio Supremo Tribunal Federal, em decisão reportada por Meirelles [...], a publicação adequada para os atos da Administração deve ser feita no órgão oficial não valendo a veiculação somente na imprensa privada, no rádio ou na televisão, enfatizando o autor que devem ser compreendidos na expressão órgão oficial, além do Diário Oficial, 'os jornais contratados' pelas entidades públicas para efetivação das publicações oficiais [...]". 
13 OS PMEs de Cachoeiras de Macacu (2015), Guapimirim (2015), Maricá (2015), Mesquita (2015a, 2015b) Nilópolis (2015), Queimados (2015) São Gonçalo (2015a, 2015b), São João de Meriti (2015) e Tanguá (2015) não tecem nenhuma referência ao processo de construção local dos seus respectivos PMEs.
Outro problema relacionado ao déficit de informações sobre os PMEs da RMRJ implica no desconhecimento acerca do histórico de sua construção local. Também se considerando os documentos em questão, apurou-se que, do conjunto desses 19 planos, apenas dez (53\%) fornecem algum tipo de referência acerca do processo de sua elaboração, sendo possível distingui-las, de forma pontual, diminuta e fragmentada nos planos de Belford Roxo (2015b), Duque de Caxias (2015b), Itaboraí (2015), Itaguaí (2015b), Magé (2015) e Nova Iguaçu (2015), e, de modo sistematizado e com mais detalhes, apenas nos PMEs de Japeri (2015b), Paracambi (2015), Rio Bonito (2015b) e Seropédica (2015b). ${ }^{13}$

\section{DIAGNÓSTICO DA SITUAÇÃO EDUCACIONAL NOS PMES}

Em um plano de educação, o diagnóstico consiste no exame de certa realidade territorial educacional (por exemplo, nacional, estadual, distrital, regional ou municipal), isso por meio da análise de indicadores quantitativos e de caracterizações e contextualizações qualitativas, compreendendo o equacionamento de problemas, dificuldades e perspectivas (BONAMINO et al., 2006; MONLEVADE, 2002; ROCHA; MONLEVADE; AGUIAR, 2006). Esses indicadores, por definição geral, podem ser considerados "sinais que chamam a atenção sobre determinados comportamentos de um sistema" (BOTTANI, 1998, p. 24) e que, com isso, expressam "uma forma de descrever o sistema” (SOARES; XAVIER, 2013, p. 920). É a partir do diagnóstico, portanto, que se estabelecem as escolhas para a formulação das políticas que vêm a dar corpo ao plano propriamente dito, em termos das suas metas/decisões e estratégias, isso com maior fidedignidade em relação a uma situação educacional específica (BORDIGNON, 2014).

Mas não basta apenas que o diagnóstico seja elaborado e venha a subsidiar a construção do plano de educação. A um só tempo, torna-se necessária sua ampla divulgação para o poder público e para a sociedade em geral, publicização que possibilita, de fato, o debate acerca da pertinência do plano, ou seja, sua avaliação no sentido lato, até mesmo configurando a diagnose em referência para que os entes federados 
possam proceder à elaboração dos seus respectivos planos em sintonia ao PNE (MARTINS, 2014). Para o MEC, em documento orientador da elaboração dos planos infranacionais - denominado Planejando a próxima década: alinhando os planos de educação -, tal publicização consiste no reforço do caráter democrático da administração pública, pois fornece "subsídios aos órgãos de controle social para exercerem o acompanhamento dos objetivos e das metas definidas nos planos" (BRASIL, 2014b, p. 16).

Em que pese à importância fundamental da ação diagnóstica para, em particular, o planejamento da educação, nota-se que a publicação do PNE 2014-2024 no Diário Oficial da União (DOU) (BRASIL, 2014a) não é acompanhada de nenhum diagnóstico que fundamente as suas metas e estratégias. ${ }^{14}$ Já no texto propriamente dito do plano, referências explícitas ao emprego do diagnóstico como meio que possibilita o conhecimento acerca de uma dada realidade educacional são pontuais, constando apenas de duas estratégias, respectivamente associadas às Metas 9 e 15, não havendo, em qualquer outro momento, alusões à sua adoção. No primeiro caso, o diagnóstico é indicado na estratégia 9.2, vinculada à meta de Educação de Jovens e Adultos (EJA), como forma de identificação da "demanda ativa por vagas" nessa modalidade de ensino (BRASIL, 2014a, Meta 9). Tal perspectiva se repete na estratégia 15.1, relativa à meta sobre Formação dos Profissionais da Educação, agora evocando a importância de um "plano estratégico que apresente diagnóstico das necessidades de formação" desses profissionais (BRASIL, 2014a, Meta 15) e que possibilite informações sobre a "capacidade de atendimento, por parte de instituições públicas e comunitárias de educação superior existentes nos Estados, Distrito Federal e Municípios [...]" (BRASIL, 2014a, Meta 15). ${ }^{15}$

No âmbito dos PMEs da RMRJ, preliminarmente cabe salientar que os planos alinhados ao PNE 2001-2010 (BRASIL, 2001) já apresentavam diversos problemas relativos ao registro do diagnóstico em questão. Pesquisa realizada por Souza e Alcântara $(2015,2016)$ evidenciou que, não obstante o fato de a grande maioria desses PMEs ter exposto, em seus respectivos planos, seção dedicada à explicitação do que
14 A ausência de diagnóstico associado ao novo PNE se faz notar antes da aprovação desse plano, ainda por época da apresentação da proposta do executivo que veio a implicá-lo - Projeto de Lei (PL) n. 8.035, de 20 de dezembro de 2010 (BRASIL, 2011). De acordo com Martins (2014), à época, foi necessário que a Câmara dos Deputados viesse a solicitar ao MEC o envio do diagnóstico que embasava a proposição para o novo plano, tendo obtido, em resposta, o encaminhamento de "notas técnicas, com dados estatísticos e análises referentes a cada meta, o que possibilitou o debate mais franco e a crítica [...]" (MARTINS, 2014, p. 16).

\footnotetext{
15 Será apenas no ano seguinte ao da aprovação do PNE Lei n. 13.005/2014 (BRASIL, 2014a) - que se observará alguma sistematização acerca da realidade educacional do país, isso associadamente às decisões desse plano. Em documento do MEC que apresenta a chamada Linha de Base do PNE, é apresentado "um panorama descritivo sobre as mudanças recentes da educação brasileira", acrescido do diagnóstico da "situação atual das metas" (BRASIL, 2015, p. 10), com vistas ao balizamento do monitoramento e avaliação da evolução do cumprimento das decisões desse plano nacional.
} 
denomina diagnóstico ou análise da situação educacional, de modo recorrente apresenta

[...] caráter vago, pois prioriza considerações de âmbito nacional, princípios expressos na LDBEN n. 9.394/1996 (BRASIL, 1996) ou perpassa problemas clássicos que marcam a educação no país, apoiando-se, sobretudo, em dados educacionais mais gerais e genéricos [...]. (SOUZA; ALCÂNTARA, 2015, p. 274)

Do conjunto de dez PMEs examinados por esses autores (já mencionados anteriormente), apenas três demonstraram maior empenho em traçar diagnósticos que viessem dar conta da situação educacional local, mapeando dados educacionais apropriados (SOUZA; ALCÂNTARA, 2016).

Já na esfera dos PMEs relacionados ao PNE 2014-2024 (BRASIL, 2014a), a maior parcela - 15 (79\%) - expõe algum tipo de registro da situação educacional local, à exceção dos planos de Cachoeiras de Macacu (2015), Maricá (2015), Nilópolis (2015) e Queimados (2015), aspecto positivo se levada em conta certa tendência de os planos infranacionais reproduzirem, em alguma medida, a organização e o conteúdo do PNE que, conforme visto, não veicula o diagnóstico sobre a realidade nacional.

Do conjunto dos 15 PMEs que, de alguma forma, aludem à realização de diagnósticos, cinco (33\%) - Duque de Caxias (2015b), Mesquita (2015a), Nova Iguaçu (2015), São Gonçalo (2015b) e São João de Meriti (2015) - organizam seus planos de modo que, para cada meta declarada, a definição das estratégias seja antecedida por análises específicas sobre a situação local da educação. Para isso, pautam-se em referenciais jurídicos e normativos, em alguns casos também em estudos acadêmico-científicos, assim como em indicadores quantitativos, como os sinalizados no Anexo 1 do presente artigo, adiante tratados. Nesses planos, embora com algumas variações, é possível observar uma relação de consequência mais imediata entre o diagnóstico efetuado - que, via de regra, culmina no equacionamento dos desafios postos à educação municipal - e a declaração das metas e das estratégias que lhe dão corpo. 
Outro agrupamento de cinco PMEs (33\%) documenta o diagnóstico em seções específicas do plano, mas esquematicamente dissociada da declaração das estratégias. No entanto, organizam essas análises situacionais ou em correspondência a cada uma das suas metas - Itaboraí (2015) e Tanguá (2015) - ou a eixos temáticos relativos, tanto aos níveis, etapas e modalidades de educação quanto a certos temas como gestão democrática, conselhos de educação, formação de professores, entre outros -, Japeri (2015b), Magé (2015) e Rio Bonito (2015b), como na organização empregada no PNE 2001-2010 (BRASIL, 2001). De um modo ou de outro, o que caracteriza esses documentos é o fato de indicarem seus respectivos diagnósticos em seções que antecedem ou dão sequência às seções que declaram as metas e diretrizes do PME, dificultando, com isso, a visualização mais imediata sobre a possível articulação entre esses elementos do planejamento. Assim como no grupo anterior, esses PMEs buscam alicerçar suas análises por meio de abordagens qualitativas e quantitativas (Anexo 1), também com vistas ao equacionamento das demandas educacionais locais.

Por fim, um terceiro conjunto, também constituído por cinco (34\%) planos, em que pese o fato de dispor de seção que realiza exposição de diversos indicadores e estatísticas dispostas em tabelas e/ou quadros, furta-se ao exame desses elementos. Com isso, ou exclusivamente, registra-os no documento - Belford Roxo (2015b) e Paracambi (2015) -, acrescentando algumas considerações de caráter genérico Guapimirim (2015) -, ou se atém a algumas breves incursões descritivas, mas não analíticas - Itaguaí (2015b) e Seropédica (2015b). Em todas essas situações, constata-se ausência de exames sobre os dados veiculados no plano, de modo que viessem a dar causa às decisões e estratégias elencadas em seções anteriores ou posteriores, o que, a nosso ver, leva à descaracterização da diagnose.

Conforme Bordignon (2014, p. 35), "Não basta conhecer a realidade atual (informações e dados estatísticos), mas é essencial compreendê-la", ou seja, a ação diagnóstica não pode reduzir-se a simples exposição de informações quantitativas, ou qualitativas, sobre o contexto educacional local, mesmo 
16 Disponivel em: <http://portal. inep.gov.br/basica-levantamentosmicrodados>. Acesso em: 11 ago. 2016

17 Disponivel em: <http://ideb inep.gov.br/resultado/resultado/ resultadoBrasil.seam>. Acesso em: 11 ago. 2016

18 Disponível em: <http://simec.mec gov.br/pde/graficopne.php>. Acesso em: 11 ago. 2016 que de forma descritiva ou exploratória, sem que se avance na perspectiva da sua interpretação crítica, de modo a permitir a apreensão das exigências educacionais do município e, em consequência, a declaração dos meios que se direcionarão ao seu encontro.

Pelo exposto, avalia-se que apenas dez (53\%) dos 19 PMEs da RMRJ enfocados por esse estudo, relativos aos dois primeiros grupos anteriormente mencionados, apresentam, de fato, exame efetivo acerca da situação educacional local, e não 15, apesar dessa diferença remeter a planos que listam indicadores e demais informações que potencialmente poderiam implicar diagnósticos producentes ao planejamento em questão.

Segundo o Anexo 1, distingue-se que a maior parcela das fontes dos dados mencionadas nos 15 PMEs que, de algum modo, alude à realização de diagnósticos sobre a realidade educacional local, é produzida pelo Instituto Nacional de Estudos e Pesquisas Educacionais Anísio Teixeira (Inep/MEC), seja englobando microdados ${ }^{16}$ relativos ao Censo Escolar da Educação Básica (Educacenso), ao Censo da Educação Superior (CES), ao Exame Nacional do Ensino Médio (Enem) e ao Sistema de Avaliação da Educação Básica (Saeb) - nesse caso, em especial, também sobressaindo dados discretos relativos à Avaliação Nacional do Rendimento Escolar (Anresc) -, seja apoiando-se no Î́ndice de Desenvolvimento da Educação Básica (Ideb) - já alcançado pelo município ou projetado para os próximos anos, até 2021 (constante do diagnóstico e/ou da Meta 7 , relativa à qualidade da educação básica) ${ }^{17}-$, confirmando o notório valor dos estudos realizados por esse órgão federal, particularmente para o planejamento da educação.

Ainda no âmbito do MEC, observa-se que alguns desses PMEs se utilizam dos indicadores disponibilizados pelo Sistema Integrado de Monitoramento, Execução e Controle do MEC (Simec)..$^{18}$ Esses ilustram graficamente a situação de cada meta da região do país, do estado, da mesorregião (por exemplo, a RM) e/ou do município em relação à situação nacional. Em particular, cabe destacar a preocupação da maior parcela dos planos que transcrevem esses indicadores em também incluir o gráfico correspondente à situação educacional 
da RMRJ, o que pode estar sinalizando certa tendência, mesmo que incipiente, de uma apreciação comparativa da realidade educacional local em escala também regional.

Igualmente recorrente entre esses PMEs é a utilização dos dados produzidos pelo Instituto Brasileiro de Geografia e Estatística (IBGE) ${ }^{19}$ resultados do Censo Demográfico (CD) e da Pesquisa Nacional por Amostra de Domicílios (Pnad). Nota-se, também, a utilização por muitos planos de dados coletados e/ou processados pela própria SME, ao lado de outros de maior especificidade a cada PME (informados nas notas do Anexo 1), produzidos por órgãos locais, estaduais, nacionais ou por organismos internacionais.

Observando-se o Anexo 1, o PME de Duque de Caxias merece destaque, pois pauta-se única e exclusivamente em dados localmente coletados em levantamento realizado pela $\mathrm{SME}^{20}$ com a comunidade. Embora importantes para revelar algumas das demandas educacionais locais, especialmente segundo a ótica da comunidade (o que corrobora, positivamente, o caráter democrático e sociopolítico do plano), esses dados não expõem suficiência para seu alinhamento técnico (e também político) em relação aos desafios postos ao planejamento mais amplo da educação, em escala nacional. No âmbito do planejamento decenal em causa, o que se encontra no centro da questão não é apenas a construção de um plano que pretenda dar conta de certos déficits educacionais locais, mas, sem perder de vista essas especificidades, estabelecer sintonia em relação ao fato de as metas serem orgânica e nacionalmente alcançadas, movimento que, em larga medida, calça-se em índices como o Ideb ${ }^{21}$ que, ao lado de outros importantes indicadores, também veio a ser desconsiderado por esse plano. No vácuo gerado por essas omissões, não se observou outro indicador que possa subsidiar, de algum modo, a avaliação desse PME.

Decerto concordamos com Popkewitz e Lindblad (2001, p. 111) quando afirmam que os relatórios de estatísticas educacionais consistem numa ficção, "pois as categorias não são reais, mas representações elaboradas para identificar e ordenar relações e permitir planejamentos sociais [...]”. Igualmente, coincidimos com as críticas de Almeida, Dalben e Freitas (2013) e
19 Disponível em: <http://www.ibge. gov.br/home/>. Acesso em: 11 ago. 2016.

20 O PME de Duque de Caxias (2015b) aclara que esse levantamento, realizado em 2010, empregou dois questionários, um primeiro aplicado às instituições da sociedade civil e às unidades escolares, versando sobre aspectos populacionais (segurança alimentar, assistência social e problemas gerais) e cultuais (informações socioculturais, esportivas e religiosas), enquanto que um segundo instrumento, aplicado apenas às unidades escolares, de natureza mais específica a respeito da rede municipal (dados físicos, formação de professores, formas de contratação dos profissionais, financiamento, gestão, escolar e questões gerais).

21 Grosso modo, o Ideb engloba, no seu cálculo, aspectos relativos ao aprendizado e à trajetória escolar dos alunos, ou seja, dados sobre aprovação escolar obtidos no Censo Escolar e médias de desempenho referentes às avaliações do Inep/Saeb, para as unidades da federação e para o país, e Anresc, para os municípios. Disponível em: <http://portal.inep.gov. br/web/portal-ideb/o-que-e-o-ideb>. Acesso em 2 ago. 2016. 
Soares e Xavier (2013) a respeito dos limites do Ideb. Os primeiros sinalizam "que os desempenhos médios obtidos [pelas instituições escolares] não podem ser traduzidos como retrato fiel da qualidade das instituições" (ALMEIDA; DALBEN; FREITAS, 2013, p. 1.155), pois a qualidade da escola ou sua eficácia são passíveis de outras representações. Já os segundos autores demarcam que esse índice carece de aperfeiçoamentos, como sua divulgação

[...] de forma contextualizada, que contenha pelo menos
uma descrição do nível socioeconômico das escolas ou
dos municípios. Idealmente, outras características das es-
colas, como sua infraestrutura, devem também ser consi-
deradas. (SOARES; XAVIER, 2013, p. 920)

Todavia, há de se ponderar que o problema em causa consiste em harmonizar o planejamento decenal local da educação ao nacional, o que significa estabelecer, conforme anteriormente enfatizado, coesão entre as metas desses PMEs e o PNE, conferindo unidade em torno das decisões e, nesse caso, incluindo-se os indicadores que as balizam e que, em consequência, deverão ser empregados para efeito do monitoramento e avaliação dos planos. Aliás, a própria Lei n. 13.005/2014 determina que as metas do PNE devam ter como referência o Pnad, o CD e os Censos Nacionais da Educação Básica e Superior (BRASIL, 2014a, art. $4^{\circ}$ ), o que, invariavelmente, abarca as decisões relativas aos planos infranacionais.

\section{METAS E ESTRATÉGIAS DOS PMES}

Conforme já sinalizado, as metas de um plano trazem à vista as decisões assumidas para explicitarem as intenções e ações das políticas educacionais a serem adotadas para a solução dos problemas identificados na etapa diagnóstica, com números e prazos mensuráveis e, ainda, com indicação das estratégias nas e pelas quais o plano se moverá ao longo da sua implementação (BORDIGNON, 2014; BONAMINO et al., 2006; MONLEVADE, 2002). Essas estratégias consistem justamente nos meios e processos que viabilizarão o alcance das 
metas do plano, expondo a definição das ações, dos recursos e das "condições favoráveis disponíveis para avançar rumo às metas” (BORDIGNON, 2014, p. 32).

De acordo com o balanço efetuado pelo Conselho Nacional de Educação (CNE) sobre os problemas que marcaram o PNE 2001-2010 (BRASIL, 2001), dentre as deformidades internas ao texto desse plano, sobressai o excessivo número de decisões/metas (295) que, em decorrência, acabou por pulverizar e fragmentar as ações previstas (BRASIL, 2009). Para Dourado (2010, p. 684), esse elevado número de decisões retrata, justamente,

[...] a carência de organicidade interna do Plano, na medida em que várias metas são reiteradas, por vezes superpostas, e, em outros casos, não apresentam a devida articulação interna [...].

Entretanto, o PNE 2014-2024 indica ter superado os problemas decorrentes do número excessivo de decisões, na medida em que se estrutura a partir de 20 metas, o que também vem a favorecer "o engajamento da sociedade civil e o controle social na execução do plano, fundamentais para seu sucesso" (MARTINS, 2014, p. 15). No seu conjunto, essas decisões visam à universalização das etapas e modalidades da educação básica, articuladamente à melhoria da sua qualidade, à ampliação, igualmente, da oferta com qualidade do ensino superior, incluindo-se o segmento de pós-graduação, passando pela qualificação e valorização dos profissionais da educação e culminando tanto no asseguramento de condições para a efetivação da gestão democrática quanto na ampliação do investimento público em educação para os almejados $10 \%$ do produto interno bruto (PIB), prevendo, ainda, seu acompanhamento e avaliação nacional e infranacional, tanto pelo poder público quanto pela sociedade civil organizada (BRASIL, 2014a, 2014b).

Em que pese o fato de o número de metas do novo PNE se mostrar exequível, o que tende a repercutir também positivamente quando da definição das decisões dos planos infranacionais, a atenção deve ser mantida agora em termos do número de estratégias. Em larga medida, as estratégias, 
22 Análises sobre a estrutura do PNE 2001-2010, assim como em relação à adotada pelos PEEs consoantes podem ser encontradas por exemplo, em Souza e Menezes (2014, 2015)

23 Além desse aspecto central, cabe salientar que esse PME apresenta, ainda, uma série de outros problemas relacionados à definição de suas decisões, como, por exemplo, (i) a duplicidade de suas listagens nos eixos temáticos, ocorrido na educação infantil - da qual consta uma listagem com 60 "Objetivos e Metas" e outra com oito "Metas e Estratégias" (DUQUE DE CAXIAS, 2015b, p. 56-61) -, e no ensino superior - no qual se nota uma listagem com 28 "Metas", seguida de outra com quatro "Metas" (DUQUE DE CAXIAS, 2015b, p. 79-81); e, ainda, (ii) a fusão de diretrizes e metas em uma única lista, como no caso do eixo relativo à Gestão Democrática (DUQUE DE CAXIAS, 2015b, p. 48 50), aspectos que tornam alguns dos objetivos desse plano incognoscíveis o que também compromete a possibilidade de o instrumento vir a ser implementado com êxito, assim como devidamente avaliado ao longo desse processo, já que, conforme anteriormente visto, números elevados de metas obstaculizam monitoramentos e avaliações efetivas.

24 A Meta 8 do PNE 2014-2014 concerne à elevação da escolaridade média da população de 18 a 29 anos, enquanto que a Meta 9 se volta para a elevação da taxa de alfabetização da população com 15 anos ou mais (BRASIL, 2014). assim como as metas/decisões de um plano, em essência, equivalem a objetivos a serem perseguidos. No entanto, esses objetivos diferem-se na medida em que as estratégias se configuram em "objetivos meios" viabilizadores das decisões/ metas, ou seja, dos "objetivos fins" do plano (BORDIGNON, 2014) e, por isso, dependendo da sua especificação quantitativa e qualitativa, podem tanto contribuir para o alcance da decisão/meta, como dela se distanciar.

Assim, o Anexo 2 enumera o conjunto das 20 decisões e estratégias do PNE 2014-2024 (BRASIL, 2014a), também especificando os números de estratégias definidas para cada um dos PMEs.

De início, cabe salientar que o plano de Duque de Caxias (2015b) não se encontra incluído na sistematização mostrada no Anexo 2 pelo fato de a organização de suas decisões não expor consonância ao modelo empregado no PNE 2014-2024 (BRASIL, 2014a), espelhando estrutura similar à adotada no PNE 2001-2010 (BRASIL, 2001)..22 Isso equivale a dizer que esse PME se organiza por eixos temáticos e subtemas a partir dos quais é indicado um extenso conjunto de diretrizes e, sobretudo, cerca de 383 objetivos/metas, o que impede o confronto com a estrutura dos demais PMEs, a começar pelo próprio PNE em vigência. ${ }^{23}$ Assim, dos 18 PMEs indicados no Anexo 2, cinco merecem destaque - Itaboraí, Maricá, Nilópolis, Rio Bonito e São Gonçalo -, como segue.

O PME de Itaboraí (2015) é o único desses 18 planos que não declara 20 metas e $\operatorname{sim} 19$, resultado da fusão das Metas 8 e 9 do PNE 2014-2024 em uma única decisão. ${ }^{24}$ Contudo, de modo a viabilizar as quantificações apresentadas no Anexo 2, optou-se em dividir proporcionalmente as 24 estratégias originais da Meta 8 do PME de Itaboraí entre essa decisão e a que sofreu integração (articulada à Meta 9 do PNE), de modo a também sintonizar as numerações desse conjunto de metas em relação ao plano nacional. Sem isso, as estratégias e metas não coincidiriam. Por exemplo, as estratégias da Meta 19 desse PME, relativas ao financiamento da educação, estariam indicadas na coluna correspondente à Meta 19 do PNE (gestão democrática da educação) e não à Meta 20, a que de fato equivale. 
Por seu turno, o plano de Maricá (2015), embora declare as 20 decisões que, a princípio, o nivelam em relação à organização do PNE 2014-2024, expõe quatro metas desvestidas de qualquer estratégia, constando do próprio plano publicado em órgão oficial o registro da informação "SUPRIMIDA" para cada uma das estratégias das seguintes decisões: Meta 3 (universalização do atendimento escolar para a população de 7 a 15 anos), com todas as 19 estratégias suprimidas (3.1 a 3.19); Meta 11 (aumento das matrículas na educação profissional), com todas as 14 estratégias suprimidas (11.1 a 11.14); Meta 12 (elevação das matrículas na educação superior), com todas as nove estratégias suprimidas (12.1 a 12.9) e, ainda, Meta 13 (qualificação de pessoal da educação superior), com todas as três estratégias suprimidas (13.1 a 13.3). Ou seja, subtende-se que esse plano, em vez de ter 20 metas, na prática, tem apenas 16, na medida em que as Metas 3, 11, 12 e 13 encontram-se desvestidas da indicação dos meios e processos que lhes dão sustentação, ou seja, não expõem exequibilidade. Desconhecendo-se as motivações de tais supressões, tampouco se sabe a respeito da sua origem, ou seja, se ocorreram na esfera da aprovação do PME pela Câmara Municipal, ou se constituem em vetos do Poder Executivo, quando da sua sanção.

Já os planos de Nilópolis, São Gonçalo e Rio Bonito se destacam em função das situações quantitativamente extremas que representam. Nilópolis (2015) consiste no PME que se poderia aqui predicar por minimalista, pois, em contraste com o restante dos planos, é o que menos estratégias apresenta (37). Das 20 metas que tem, 17 são caracteristicamente compostas por uma ou, no máximo, duas estratégias, o que configura esse plano num instrumento desafiador do ponto de vista de sua implementação, pois, majoritariamente, não mais do que dois caminhos são traçados para alcance da maior parcela das suas decisões, o que, decerto, restringe sua efetividade, subestimando a complexidade que cerca a consecução das decisões tomadas. Importante também notar que o segundo plano com menos estratégias consiste no PME de Japeri (2015b), com 125, mesmo assim com 88 estratégias a mais do que Nilópolis (2015). 
No polo diametralmente oposto ao que se sucede com o PME de Nilópolis, os planos de São Gonçalo (2015b) e Rio Bonito (2015b) trazem à vista os dois maiores números de estratégias, respectivamente 322 e 319 . Nesse sentido, têm, nessa ordem, cerca de $27 \%$ e $25 \%$ de meios e processos a mais do que os 254 apresentados pelo PNE 2014-2024 (veja-se Anexo 2). Embora tais diferenças não pareçam tão relevantes, cabe destacar que, se, por um lado, esses PMEs se encontram poupados da pulverização e fragmentação de suas metas - conforme o ocorrido com o PNE 2001-2010 (BRASIL, 2001) -, correm o risco de que o empoar agora se verifique na consecução das estratégias que dão corpo às suas metas, dificultando, com isso, a implementação do plano propriamente dito.

Uma última consideração acerca do Anexo 2 também concerne às situações numéricas extremas, agora relacionadas às metas que mais e menos atenção receberam por parte dos 18 PMEs em questão. Nesse sentido, observa-se que as Metas 4 e 7 são aquelas que aglutinam o maior número de estratégias, respectivamente 441 e 354, sinalizando tendências igualmente observadas no PNE 2014-2024, no qual a Meta 7 é a que mais reúne estratégias (36), seguida, em terceiro lugar, da Meta 4 (19). Denotam, portanto, maior cuidado em assegurar, de um lado, a universalização da educação básica e o atendimento educacional especializado para a "população de quatro a 17 (dezessete) anos com deficiência, transtornos globais do desenvolvimento e altas habilidades ou superdotação" (BRASIL, 2014a, Meta 4) e, de outro, a qualidade desse nível de ensino "em todas as etapas e modalidades, com melhoria do fluxo escolar e da aprendizagem” (BRASIL, 2014a, Meta 7). Decerto, há muito tempo que a educação especial se constitui em ponto crítico da educação municipal, particularmente em face da problemática da capacitação docente nessa área e dos recursos logísticos demandados que, em particular, refletem-se nas dificuldades de atendimento de alunos com necessidades especiais em classes comuns das escolas municipais (FERREIRA; GLAT, 2003). Em relação à qualidade da educação básica, trata-se de questão polêmica, sobretudo quando remete às fragilidades dos sistemas 
municipais de ensino do país (NARDI; SCHNEIDER; RIOS, 2014; PADILHA et al., 2012), além das constatações de que os recentes avanços de sua melhoria vêm ocorrendo de modo desigual entre os estudantes das camadas sociais economicamente mais altas e mais baixas da população (GOIS, 2016). ${ }^{25}$

O outro extremo de número de estratégias para o qual o Anexo 2 chama a atenção refere-se às Metas 13 e 14, que exibem o menor número total de estratégias desses planos, respectivamente 72 e 94 . Trata-se de duas metas relacionadas à educação superior, cujo atendimento não se constitui em prioridade dos municípios (BRASIL, 1996), mas que, de algum modo, não deixam de ser contempladas por esses PMEs, quer em função da previsão de colaboração por parte do estado do Rio de Janeiro e da rede federal de instituições de ensino superior, quer por meio de parcerias com instituições privadas. Assim, enquanto a primeira meta visa a "elevar a qualidade da educação superior e ampliar a proporção de mestres e doutores do corpo docente em efetivo exercício no conjunto do sistema de educação superior" (BRASIL, 2014a, Meta 13), a segunda objetiva a elevação gradual do "número de matrículas na pós-graduação stricto sensu” (BRASIL, 2014a, Meta 14).

No seu conjunto, os extremos superior e inferior relativos ao número de estratégias das metas dos 18 PMEs indicados no Anexo 2 acabam se justificando, seja pela importância e complexidade do seu atendimento local, seja por não se constituírem prioridade de cobertura em âmbito municipal.

\section{CONSIDERAÇÕES FINAIS}

Conforme visto, parecem ser muitos os avanços relativos aos novos PMEs da RMRJ, a começar pelo significativo crescimento do número de municípios metropolitanos que vieram a aderir à sua elaboração (no contexto do PNE 2001-2010, não mais do que $53 \%$, enquanto que na esfera do novo PNE, cerca de $90 \%$ ). A um só tempo, merece destaque o fato de que: (i) embora somente $42 \%$ dessas localidades vieram a transformar o PME em norma jurídica no prazo estipulado pela Lei n. 13.005/2014 (BRASIL, 2014a), os atrasos das demais
25 Em sua reportagem, Gois (2016) faz referência a estudo inédito dos pesquisadores da Universidade Federal de Minas Gerais, José Francisco Soares e Victor Maria Senna Delgado. 
podem ser ajuizados como não comprometedores do alinhamento de prazos relativos às metas nacionais e municipais, à exceção dos PMEs de Niterói e Rio de Janeiro, que já expõem retardos superiores a um ano; (ii) metade desses PMEs efetivamente registrou o diagnóstico que sustenta as decisões do plano, operando por meio de um extenso e diverso conjunto de indicadores educacionais e sociais, expressão do esforço em apreender a complexidade que cerca o exame da situação educacional local; (iii) a quase totalidade definiu metas e estratégias numericamente exequíveis, coerentemente à organização que edifica o PNE 2014-2024.

Ainda do ponto de vista do seu conjunto, há outro aspecto favorável a esses PMEs, que consiste na identificação de certa tendência, mesmo que diminuta, de algumas decisões também apontarem a situação regional-metropolitana da meta, isso com base nos indicadores disponibilizados pelo Simec. Embora tal fato não necessariamente implique considerar movimento em torno de uma possível cooperação intermunicipal entre esses planos, sugere, no mínimo, certo interesse em confrontar a realidade da educação local com a mesorregional que sequer foi mencionada na versão anterior desses PMEs. Conforme identificado nos estudos de Souza e Alcântara $(2015,2016)$, os planos da RMRJ alinhados ao extinto PNE 2001-2010 (BRASIL, 2001) encontravam-se integralmente desvestidos de referências a essa RM. De um modo ou de outro, continua-se a não observar elementos de planejamento que indiquem cooperação intermunicipal, pois, assim como nos PMEs pregressos,

[...] se constatou a ausência de um enfoque regional-metropolitano no conjunto de decisões desses planos, o que caracteriza certo isolamento entre os planejamentos locais da educação, e entre estes e um possível planejamento integrado para a área". (SOUZA; ALCÂNTARA, 2016)

Ao lado dos problemas relacionados a pouca transparência da publicação em órgão oficial das leis e/ou planos propriamente ditos, por parte da metade desses municípios, é possível afirmar que as questões mais críticas que marcam a organização do conjunto dos PMEs analisados consistem: 
(i) no reduzido número de planos (não mais da metade) que registra algum tipo de referência sobre sua elaboração local, sendo possível distingui-la, de modo sistematizado, em poucos documentos, prevalecendo, nos demais, informações genéricas e fragmentadas; e (ii) na evidência de que apenas metade chega a registrar o necessário diagnóstico sobre a realidade educacional local, enquanto que os demais planos ou o reduzem a uma simples exposição de indicadores quantitativos ou nenhuma informação a seu respeito veiculam.

Conclusivamente, postula-se que apenas cerca da metade - nove (47\%) - dos PMEs da RMRJ não apresenta problemas significativos em torno da sua organização, a saber, Itaboraí, Japeri, Magé, Mesquita, Nova Iguaçu, Rio Bonito, São Gonçalo, São João de Meriti e Tanguá. Os demais dez (53\%) PMEs, ainda circunscritamente às dimensões privilegiadas neste estudo (normatização jurídica, diagnóstico da situação educacional e definição das metas e estratégias), expõem problemas em um ou mais desses indicadores. Como casos mais graves, que implicam, de fato, importantes desalinhamentos em relação ao PNE 2014-2024, destacam-se os PMEs de: (i) Duque de Caxias, cuja estrutura e organização se distanciam integralmente daquela empregada por esse plano nacional, além do fato de não ter realizado diagnóstico ancorado em nenhum dos dados que servem às metas desse plano nacional; (ii) Maricá, que embora declare 20 decisões, suprime inteiramente as estratégias de quatro dessas metas, inviabilizando-as; e, ainda, (iii) Nilópolis, que expõe significativa insuficiência de estratégias de sustentação das metas indicadas - apenas 37 , correspondente, em termos médios, à taxa de 1,8 estratégias por meta -, isso sem levar em conta o fato de esses dois últimos planos não portarem qualquer informação relativa ao diagnóstico que baliza as decisões tomadas.

É claro que este estudo não encerra o exame acerca dos PMEs da RMRJ relacionados ao PNE 2014-2024, propondo-se, portanto, que seja tomado como esforço de avaliação preliminar sobre esses instrumentos de planejamento local da educação, havendo múltiplas dimensões organizativas e estruturais ainda a serem contempladas, por exemplo: a propriedade dos indicadores das metas/decisões em 
viabilizar o monitoramento e a avaliação do plano, as articulações internas entre as estratégias dessas metas, as vinculações do plano com outros instrumentos de gestão local da educação, os mecanismos de financiamento, o papel atribuído aos diversos conselhos de educação na sua implementação local, entre outros. A um só tempo, em conformidade ao previsto pela Lei n. 13.005/2014, tem-se ainda pela frente "o acompanhamento local da consecução das metas deste PNE e dos planos previstos no art. $8^{\circ}$ [planos estaduais e municipais, e do Distrito Federal]" (BRASIL, 2014a, art. $6^{\circ}$, § $3^{\circ}$ ) que, para além da pretendida avaliação aqui realizada, colocará empiricamente em causa a eficiência, a eficácia e/ou a efetividade desses PMEs.

\section{REFERÊNCIAS}

ALMEIDA, Luana Costa; DALBEN, Adilson; FREITAS, Luis Carlos de. O Ideb: limites e ilusões de uma política educacional. Educação \& Sociedade, Campinas, SP, v. 34, n. 125, p. 1153-1174, out./dez. 2013.

BELFORD ROXO (Município). Lei n. 1.529, de 24 de junho de 2015. Aprova o Plano Municipal de Educação do Município de Belford Roxo - Estado do Rio de Janeiro e dá outras providencias. Hora H, Nova Iguaçu, RJ, 26 jun. 2015a. p. 9.

BELFORD ROXO (Município). Secretaria Municipal de Educação, Esporte e Turismo. Plano Municipal de Educação de Belford Roxo 2015-2025. Belford Roxo, RJ: SEMEST, $2015 b$.

BONAMINO, Alicia et al. Avaliação de políticas educacionais. In: BRASIL. Ministério da Educação. Secretaria de Educação Básica. Pradime: Programa de Apoio aos Dirigentes Municipais de Educação. Brasília, DF: MEC/SEB, 2006. p. 133-176 (Caderno de Textos, 1).

BORDIGNON, Genuíno. Planos de governo e políticas de estado: muitos planos, pouco planejamento. In: SOUZA, Donaldo Bello de; MARTINS, Ângela Maria (Org.). Planos de educação no Brasil: planejamento, políticas, práticas. São Paulo: Loyola, 2014. p. 29-53.

BOTTANI, Norberto. Ilusão ou ingenuidade? Indicadores de ensino e políticas educacionais. Educação \& Sociedade, Campinas, SP, v. 19, n. 65, p. 23-64, dez. 1998.

BRASIL. Decreto-lei n. 4.657, de 4 de setembro de 1942. Lei de Introdução ao Código Civil Brasileiro. Diário Oficial da União [da] República Federativa do Brasil, Rio de Janeiro, 9 set. 1942. 
BRASIL. Lei Complementar n. 20, de 1 de julho de 1974. Dispõe sobre a criação de estados e territórios. Diário Oficial da União [da] República Federativa do Brasil, Brasília, DF, 1 jul. 1974.

BRASIL. Constituição (1988) da República Federativa do Brasil. Diário Oficial da União [da] República Federativa do Brasil, Brasília, DF, 5 out. 1988.

BRASIL. Lei n. 9.394, de 20 de dezembro de 1996. Estabelece as Diretrizes e Bases da Educação Nacional. Diário Oficial [da] República Federativa do Brasil, Brasília, DF, 23 dez. 1996.

BRASIL. Lei n. 10.172, de 9 de janeiro de 2001. Aprova o Plano Nacional de Educação (PNE). Diário Oficial da União [da] República Federativa do Brasil, Brasília, DF, 10 jan. 2001.

BRASIL. Conselho Nacional de Educação. Portaria CNE/CP n. 10, de 6 de agosto de 2009. Indicações para subsidiar a construção do Plano Nacional de Educação 2011-2020. Brasília, DF: CNE/CP, 2009.

BRASIL. Lei n. 12.376, de 30 de dezembro de 2010. Altera a ementa do Decreto-lei n. 4.657, de 4 de setembro de 1942. Diário Oficial da União [da] República Federativa do Brasil, Brasília, DF, 31 dez. 2010.

BRASIL. Projeto de Lei do Plano Nacional de Educação (PNE 2011-2020): projeto em tramitação no Congresso Nacional - PL n. 8.035/2010. Brasília, DF: Câmara dos Deputados: Câmara, 2011 (Ação Parlamentar, 436).

BRASIL. Lei n. 13.005, de 25 de junho de 2014. Aprova o Plano Nacional de Educação - PNE e dá outras providências. Diário Oficial da União [da] República Federativa do Brasil, Brasília, DF, 26 jun. 2014a.

BRASIL. Ministério da Educação. Secretaria de Articulação com os Sistemas de Ensino. Planejando a próxima década: alinhando os planos de educação. Brasília, DF: MEC/SASE, 2014b.

BRASIL. Ministério da Educação. Secretaria de Articulação com os Sistemas de Ensino. Planejando a próxima década: conhecendo as 20 metas do Plano Nacional de Educação. Brasília, DF: MEC/SASE, 2014c.

BRASIL. Ministério da Educação. Instituto Nacional de Estudos e Pesquisas Educacionais Anísio Teixeira. Plano Nacional de Educação PNE 2014-2024: linha de base. Brasília, DF: MEC/Inep, 2015.

BRITO, Fausto. O deslocamento da população brasileira para as metrópoles. Estudos Avançados, São Paulo, v. 20, n. 57, p. 221-236, maio/ago. 2006.

CACHOEIRAS DE MACACU (Município). Lei n. 2.056, de 24 de junho de 2015. Aprova o Plano Municipal de Educação - PME e dá outras providências. Diário Oficial Cachoeiras de Macacu, Cachoeiras de Macacu, n. 589, p. 2-5, 26 jun. 2015.

DIDONET, Vital. Plano Nacional de Educação (PNE). Brasília, DF: Plano, 2000.

DIDONET, Vital. O Plano Nacional de Educação e os planos estaduais e municipais: uma conquista histórica. Gestão em Rede, Curitiba, n. 33, p. 14-19, nov./dez. 2001. 
DOURADO, Luiz Fernandes. Avaliação do Plano Nacional de Educação 2001-2009: questões estruturais e conjunturais de uma política. Educação \& Sociedade, Campinas, SP, v. 31, n. 112, p. 677-705, jul./set. 2010.

DUQUE DE CAXIAS (Município). Lei n. 2.713, de 30 de junho de 2015. Aprova a adequação do Plano Municipal de Educação para o decênio 2015/2025 e dá outras providências. Boletim Oficial do Município de Duque de Caxias, Duque de Caxias, n. 6.241, p. 3, 30 jun. 2015a.

DUQUE DE CAXIAS (Município). Secretaria Municipal de Educação. Plano Municipal de Educação: PME II Confeduc. Duque de Caxias, RJ: SME, 2015b.

FERREIRA, Júlio Romero; GLAT, Rosana. Reformas educacionais pós-LDB: a inclusão do aluno com necessidades especiais no contexto da municipalização. In: SOUZA, Donaldo Bello de; FARIA, Lia Ciomar Macedo de. Desafios da educação municipal. Rio de Janeiro: DP\&A, 2003. p. 372-390.

GOIS, Antônio. Horizonte preocupante. O Globo, Rio de Janeiro, 15 ago. 2016. Sociedade, p. 17.

GUAPIMIRIM (Município). Lei n. 859, de 24 de junho de 2015. Aprova o Plano Municipal de Educação de Guapimirim 2015-2025 e dá outras providências. Boletim Informativo Oficial do Município de Guapimirim, Guapimirim, v. 16, n. 150, p. 17-36, jun. 2015.

ITABORAÍ (Município). Lei n. 2.556, de 22 de junho de 2015. Adequa o Plano Municipal de Educação, em consonância com as diretrizes, metas e estratégias previstas no Plano Nacional de Educação, aprovado pela Lei Federal n. 13.005, de 25 de junho de 2014. Itaboraí, RJ, 2015.

ITAGUAí (Município). Lei n. 3.324, de 30 de junho de 2015. Institui o Plano Municipal de Educação, na conformidade do artigo 239 da Lei Orgânica do Município de Itaguaí - Estado do Rio de Janeiro. Itaguaí, RJ, 2015a.

ITAGUAÍ (Município). Secretaria Municipal de Educação e Cultura. Plano Municipal de Educação de Itaguaí 2015-2025: educar para a mudança participação, responsabilidade e ação. Itaguaí, RJ: SMEC, 2015b.

JAPERI (Município). Lei n. 1.301, de 23 de junho de 2015. Dispõe sobre aprovação do Plano Municipal de Educação para o decênio 2015-2025, na forma a seguir especificada, e adota outras providências. Japeri, RJ, 2015a.

JAPERI (Município). Secretaria Municipal de Educação. Plano Municipal de Educação. Japeri, RJ: SMEC, 2015b.

KETELE, Jean-Marie de; ROEGIERS, Xavier. Metodologia da recolha de dados: fundamentos dos métodos de observações, de questionários, de entrevistas e de estudo de documentos. Lisboa: Instituto Piaget, 1993. (Epistemologia e Sociedade).

MAGÉ (Município). Lei n. 2.267, 1 de julho de 2015. Institui e aprova o Plano Municipal de Educação de Magé - PME e dá outras providências. Magé, RJ, 2015.

MARICÁ (Município). Lei n. 2.613, de 17 de setembro de 2015. Aprova o plano Municipal de Educação para o decênio 2015-2025 e dá outras providências. Jornal Oficial de Maricá, Maricá, v. 7, n. 605, p. 2-8, out. 2015. 
MARTINS, Paulo de Sena. Planejamento e plano nacional de educação. Cadernos Aslegis, Brasília, DF, n. 39, p. 91-118, jan./abr. 2012.

MARTINS, Paulo de Sena. A história do PNE e os desafios da nova lei. In: BRASIL. Plano Nacional de Educação 2014-2024: Lei n. 13.005, de 25 de junho de 2014, que aprova o Plano Nacional de Educação (PNE) e dá outras providências. Brasília, DF: Câmara dos Deputados, 2014, p. 9-42. (Série Legislação, 125).

MENDONÇA, Erasto Fortes. Plano Nacional de Educação: desdobramentos na política nacional. In: TEIXEIRA, Lúcia Helena G. (Org.). LDB e PNE: desdobramentos na política educacional brasileira. São Bernardo do Campo, SP: UMESP, 2002. p. 13-54. (Cadernos Anpae, 1).

MESQUITA (Município). Anexo da Lei n. 908, de 29 de junho de 2015. Omitido da publicação de 30 de junho de 2015 - Plano Municipal de Educação Mesquita 2015. Jornal de Hoje-Atos Oficiais, Mesquita, p. 2-32, 25 jul. 2015a.

MESQUITA (Município). Lei n. 908, de 29 de junho de 2015. Aprova o Plano Municipal de Educação - PME e dá outras providências. Jornal de Hoje-Atos Oficiais, Mesquita, p. 1, 30 jun. 2015b.

MONLEVADE, João Antônio Cabral de. Plano municipal da educação: fazer para acontecer. Brasília, DF: Idéa, 2002.

NARDI, Elton Luiz; SCHNEIDER, Marilda Pasqual; RIOS, Mônica Piccione Gomes. Qualidade na educação básica: ações e estratégias dinamizadoras. Educação \& Realidade, Porto Alegre, v. 39, n. 2, p. 359-390, abr.jjun. 2014.

NILÓPOLIS (Município). Lei Ordinária n. 6.490, de 3 de setembro de 2015. Aprova o Plano Municipal de Educação do município de Nilópolis para o decênio (2015-2024) e dá outras providências. A Voz dos Municípios Fluminenses, Nilópolis, v. 62, n. 3.098, p. 13-14, set. 2015.

NOVA IGUAÇU (Município). Lei n. 4.504, de 23 de junho de 2015. Dispõe sobre o Plano Municipal de Educação para o decênio 2015-2025, na forma a seguir especificada, e adota outras providências. ZM Notícias-Atos Oficiais, Nova Iguaçu, p. 2-23, 24 jun. 2015.

OLIVEIRA, Dalila Andrade de. Das políticas de governo à política de estado: reflexões sobre a atual agenda educacional brasileira. Educação \& Sociedade, Campinas, SP, v. 32, n. 115, p. 323-337, abr.jjun. 2011.

PADILHA, Frederica et al. As regularidades e exceções no desempenho no Ideb dos municípios. Estudos em Avaliação Educacional, São Paulo, v. 23, n. 51, p. 58-81, jan./abr. 2012.

PARACAMBI (Município). Lei n. 1.169, de 18 de junho de 2015. Aprova e institui o Plano Municipal de Educação de Paracambi, para os fins que menciona, e dá outras providências. ZM Notícias-Atos Oficiais, Nova Iguaçu, 4 jul. 2015. Disponível em: <http://simec.mec.gov.br/sase/sase_mapas. php?uf=RJ\&tipoinfo=1>. Acesso em: 06 maio 2016.

POPKEWITZ, Tom; LINDBLAD, Sverker. Estatísticas educacionais como um sistema de razão: relações entre governo da educação e inclusão e exclusão sociais. Educação \& Sociedade, Campinas, SP, v. 22, n. 75, p. 111-148, ago. 2001. 
QUEIMADOS (Município). Lei n. 1.251, de 15 de julho de 2015. Aprova o Plano Municipal de Educação - PME e dá outras providências. Diário Oficial do Município de Queimados, Queimados, v. 3, n. 627, p. 2-17, 4 ago. 2015.

RIO BONITO (Município). Lei n. 2.070, de 23 de junho de 2015. Ajusta o Plano Municipal de Educação de Rio Bonito, em conformidade com a Lei Federal 13.005 de 24 de junho de 2014 e dá outras providências. Rio Bonito, RJ, 2015a. Disponível em: <http://simec.mec.gov.br/sase/sase_mapas. php?uf=RJ\&tipoinfo=1>. Acesso em: 06 maio 2016.

RIO BONITO (Município). Secretaria Municipal de Educação. Plano Municipal de Educação de Rio Bonito: decênio 2015-2025, Rio Bonito, RJ: SME, 2015b.

RIO DE JANEIRO (Estado). Fundação Centro Estadual de Estatísticas, Pesquisas e Formação de Servidores Públicos do Rio de Janeiro. Anuário estatístico do Estado do Rio de Janeiro 2010. Rio de Janeiro: CEPERJ, 2010. (CD-ROM).

RIO DE JANEIRO (Estado). Lei Complementar n. 158, de 26 de dezembro de 2013. Altera o artigo $1^{\circ}$ da Lei Complementar n. 87, de 16 de dezembro de 1997, com a nova redação dada pela Lei Complementar n. 97, de 2 de outubro de 2001, a Lei Complementar n. 105, de 4 de julho de 2002, a Lei Complementar n. 130, de 21 de outubro de 2009, e a Lei Complementar n. 133, de 15 de dezembro de 2009. Diário Oficial do Estado, Rio de Janeiro, 27 dez. 2013.

ROCHA, Denise Cristina Corrêa da; MONLEVADE, João Antonio Cabral de; AGUIAR Rui Rodrigues. Financiamento e gestão orçamentária da educação. In: BRASIL. Ministério da Educação. Secretaria de Educação Básica. Pradime: Programa de Apoio aos Dirigentes Municipais de Educa. Brasília, DF: MEC/SEB, 2006. p. 73-118. (Caderno de Textos, 2).

ROLNIK, Raquel; SOMEKH, Nadia. Governar as metrópoles: dilemas da recentralização. São Paulo em Perspectiva, São Paulo, v. 14, n. 4, p. 83-90, out./dez. 2000.

SÃO GONÇALO (Município). Lei n. 658, de 7 de dezembro de 2015. Aprova o Plano Municipal de Educação do Município de São Gonçalo e dá outras providências. Atos Oficiais-Gabinete do Prefeito, São Gonçalo, p. 1, 9 dez. 2015a.

SÃO GONÇALO (Município). Plano Municipal de Educação de São Gonçalo 2015/2024. Atos Oficiais-Gabinete do Prefeito, São Gonçalo, p. 1-23, 8 dez. 2015b.

SÃO JOÃO DE MERITI (Município). Lei n. 2.004, de 17 de junho de 2015. Aprova e institui o Plano Municipal de Educação para o decênio 2014/2024. Diário Oficial da Cidade de São João de Meriti, São João de Meriti, v. 13, n. 4.210, p. 2-58, 26 jun. 2015.

SEROPÉDICA (Município). Lei n. 566, de 1 de julho de 2015. Dispõe sobre o novo Plano Municipal de Educação de Seropédica e dá outras providências. Itaguaí, 22 jul. 2015a. Disponível em: <https://leismunicipais.com.br/a/rj/s/ seropedica/lei-ordinaria/2015/57/566/lei-ordinaria-n-566-2015-dispoe-sobre-onovo-plano-municipal-de-educacao-de-seropedica-e-da-outras-providencias $>$. Acesso em: 06 maio 2016.

SEROPÉDICA (Município). Secretaria Municipal de educação, Cultura e Esporte. Plano Municipal de Educação de Seropédica 2015-2025. Itaguaí, RJ: SMEC, 2015b. 
SOARES, Evanna. A publicação dos atos administrativos e das leis municipais na imprensa oficial à luz do princípio constitucional da publicidade. Revista Jus Navigandi, Teresina, v. 13, n. 1.982, 4 dez. 2008. Disponível em: $<$ https://jus.com.br/artigos/12040>. Acesso em: 18 fev. 2016.

SOARES, José Francisco; XAVIER, Flávia Pereira. Pressupostos educacionais e estatísticos do Ideb. Educação \& Sociedade, Campinas, SP, v. 34, n. 124, p. 903-923, jul./set. 2013.

SOUZA, Donaldo Bello de; ALCÂNTARA, Alzira Batalha. Acompanhamento e avaliação de planos municipais de educação metropolitanos: o protagonismo local dos sistemas de ensino. In: SOUZA, Donaldo Bello de; DUARTE, Marisa Ribeiro Teixeira; OLIVEIRA, Rosimar de Fátima (Org.). Sistemas educacionais: concepções, tensões, desafios. São Paulo: Edições Loyola, 2015. p. 263-282.

SOUZA, Donaldo Bello de; ALCÂNTARA, Alzira Batalha. (Des)vinculações de Planos Municipais de Educação metropolitanos com outros instrumentos de gestão local da educação. Educação e Pesquisa, São Paulo, Ahead of print, p. 1-16, abr. 2016.

SOUZA, Donaldo Bello de; MENEZES, Janaína Specht da Silva. Estruturação temática dos Planos Estaduais de Educação 2001-2010: deficiências e debilidades. Rio de Janeiro: Nephem/FE/UERJ; Neephi/CCHS/Unirio, 2014 (digitado).

SOUZA, Donaldo Bello de; MENEZES, Janaína Specht da Silva. Elaboração e aprovação de planos de educação no Brasil: do nacional ao local. Ensaio: Avaliação e Políticas Públicas em Educação, Rio de Janeiro, v. 23, n. 89, p. 901-936, out./dez. 2015.

TANGUÁ (Município). Lei n. 971, de 24 de junho de 2015. Aprova o Plano Municipal de Educação para o decênio 2015-2025 e dá outras providências. Tanguá, RJ: 2015.

VIEIRA, Sofia Lerche. Planos e políticas educacionais: das concepções às práticas no Brasil. In: SOUZA, Donaldo Bello de; MARTINS, Ângela Maria (Org.). Planos de educação no Brasil: planejamentos, políticas, práticas. São Paulo: Loyola, 2014. p. 55-72.

YANG, Rui. Comparações entre políticas. In: BRAY, Mark; ADAMSON, Bob; MASON, Mark (Org.). Pesquisa em educação comparada: abordagens e métodos. Brasília, DF: Liber Livro, 2015. p. 319-343.

\section{DONALDO BELLO DE SOUZA}

Professor Associado do Departamento de Políticas Públicas, Avaliação e Gestão da Educação (DEPAG) e Coordenador do Núcleo de Estudos em Política e História da Educação Municipal (NEPHEM) da Faculdade de Educação da Universidade do Estado do Rio de Janeiro (UERJ), Rio de Janeiro, Rio de Janeiro, Brasil http://orcid.org/0000-0002-9146-5254 donaldobello@gmail.com 


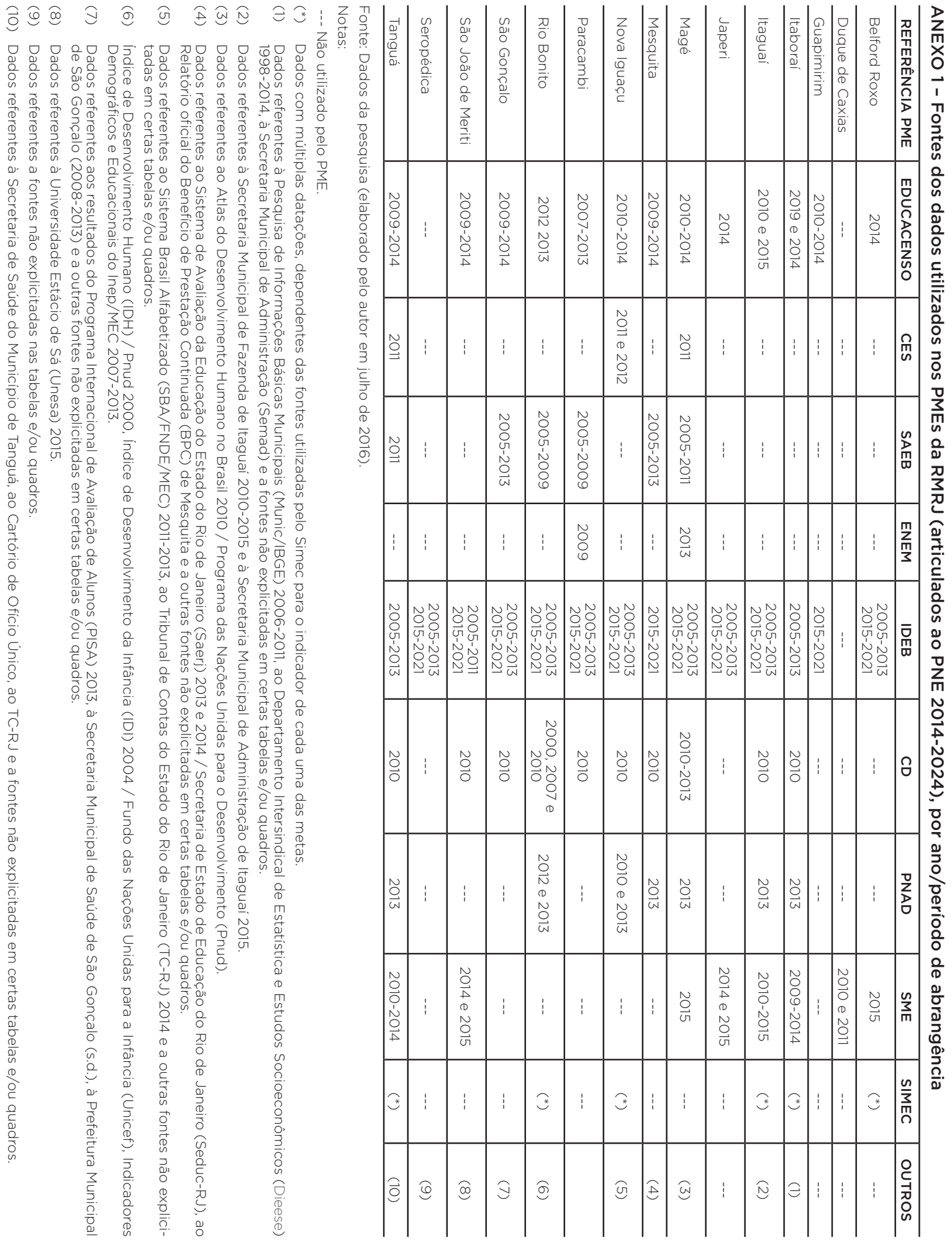




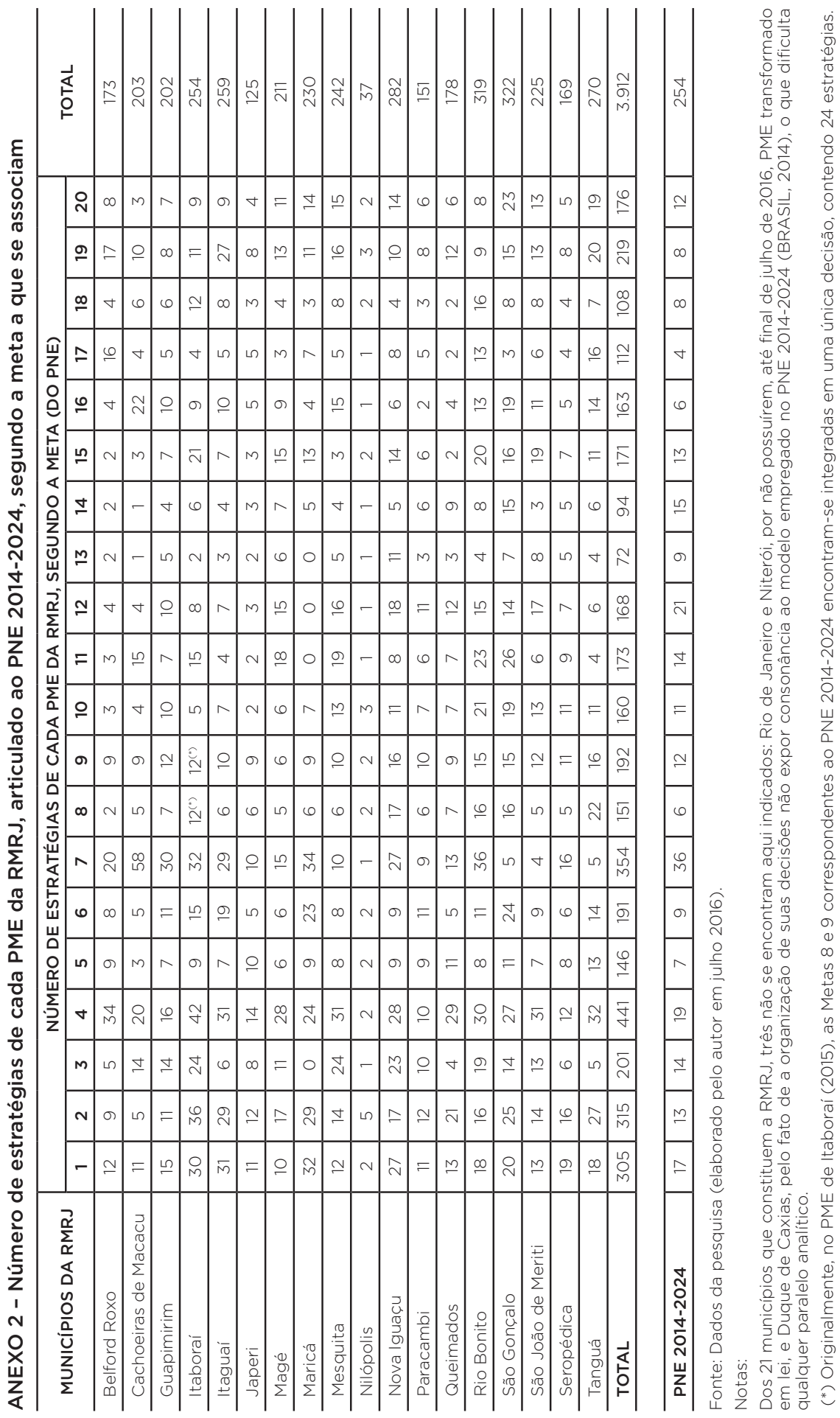

